\title{
ERRATA
}

Artigo publicado sem a inclusão do autor Eduardo Antonio da Cunha.

\section{Soybean silage and sugarcane tops silage on lamb performance}

Silagem de soja e silagem de ponta de cana no desempenho de cordeiros

\section{Josiane Aparecida de Lima ${ }^{I^{*}}$ Ivana Lícia de Campos Gavioli' ${ }^{\text {Cr }}$ Cristina Maria Pacheco Barbosa ${ }^{\mathrm{II}}$ Alexandre Berndt ${ }^{\mathrm{I}}$ Flávia Maria de Andrade Gimenes ${ }^{\mathrm{I}}$ Claudia Cristina de Paro Paz Eduardo Antonio da Cunha ${ }^{\mathrm{I}}$}

Para a versão correta, acesse: http://www.scielo.br/pdf/cr/v43n8/a21513cr2012-0487.pdf

IInstituto de Zootecnia (IZ), Rua Heitor Penteado, Nº 56, 13460-000, Nova Odessa, SP, Brasil. E-mail: josianeiz@hotmail.com.*Autor para correspondência.

IIPrograma de Pós-graduação em Produção Animal Sustentável, IZ, Nova Odessa, SP, Brasil.

IIIAgência Paulista de Tecnologia dos Agronegócios (APTA), Itapetininga, SP, Brasil. Received 07.03.12 Approved 12.23.12 Returned by the author 06.03.13
CR-2012-0487.R1 